\title{
Feinde im Labor - Milbenfraß in der Mykothek
}

\author{
Enemies in the Lab - Mite Muck in the Mycotheca
}

Autoren

Institut
P. Nenoff, J. Herrmann

Laboratorium für medizinische Mikrobiologie, Partnerschaft Dr. Jürgen Herrmann \& Prof. Dr. Pietro Nenoff

\section{Bibliografie}

DOI $10.1055 / \mathrm{s}-2007-966086$

Akt Dermatol 2007; 33;

70-71 ๑ Georg Thieme

Verlag KG Stuttgart · New York ISSN 0340-2541

Korrespondenzadresse

Prof. Dr. med. Pietro Nenoff

Laboratorium für medizinische Mikrobiologie

Partnerschaft Dr. Jürgen Herrmann \& Prof. Dr. Pietro Nenoff Straße des Friedens 8 04579 Mölbis

info@mykologie-experten.de

\section{Zusammenfassung \\ $\nabla$}

Diverse Pilzmilben - u.a. Tarsonemus interruptus, Tarsonemus fusarii Cooreman 1941 und Tarsonemus confusus - befallen vorzugsweise lange aufbewahrte Pilzkulturen, insbesondere die sog.

\section{Einleitung \\ $\nabla$}

Ein ewig aktuelles Problem für den Dermatomykologen ist der Befall der Pilzkolonien mit Pilzmilben. Sowohl Dermatophyten als auch Schimmelpilze können betroffen sein. Insbesondere dann, wenn Pilzkulturen - entweder auf Nährmedien in Petrischalen oder auf Schrägagar in Glas- bzw. Plastikkolben - über einen längeren Zeitraum im Praxislabor deponiert werden, ist mit dem sog. Milbenfraß zu rechnen.

Gefürchtet ist der Milbenbefall der Mykothek, in welcher Pilzstämme für Vergleichszwecke meist über Wochen, im Einzelfall auch über Monate, erhalten bleiben sollen, um danach erneut auf frische Nährmedien überimpft zu werden.

\section{Pilzmilben \\ $\nabla$}

Beschrieben sind mehrere Milbenarten als Verursacher des Milbenfraßes von Pilzkulturen, z.B. Tarsonemus interruptus (erstmals 1928 in Kulturen des Pilzes Conidiophora cerebella nachgewiesen und veröffentlicht), außerdem Tarsonemus fusarii Cooreman 1941 und Tarsonemus confusus [1-4]. Wie alle Arachnoiden verfügen die Milben über vier Beinpaare, nur als Larvenstadien treten sechsbeinige Formen auf ( $\bullet$ Abb. 1a, b, - Abb. 2a-c). Neben der sexuellen Fortpflanzung ist bei Tarsonemus fusarii Parthenogenese beobachtet worden. Aus den unbefruchteten Eiern entstehen dabei sowohl weibliche als auch männliche Tiere. Damit erklärt sich die Vermeh-
Mykothek, und zerstören diese manchmal irreversibel. Nachdem man den Milbenbefall erkannt hat, gibt es wenige Möglichkeiten der Behandlung, im Vordergrund stehen prophylaktische Maßnahmen.

rungsrate der Milben, die das rasche Ausbreiten der Schädlinge auf den Pilzkulturen begünstigt [5].

Man erkennt den Milbenfraß makroskopisch an einer ungleichmäßigen Oberfläche der Pilzkolonien, dem Fehlen von Teilen derselben, am besten natürlich an den charakteristischen, oft gewundenen Gängen. Problematisch ist jedoch, dass visuell scheinbar intakte Pilzkolonien durchaus von Pilzmilben befallen sein können. Da die Milben sich leicht ausbreiten bzw. auch auf noch nicht befallenen Kulturschalen verschleppt werden können, droht der Verlust bzw. die Vernichtung des gesamten Bestandes der Mykothek. Die winzigen Spinnentiere vermehren sich außerordentlich schnell und vermögen selbst die Stopfen der Kulturröhrchen zu durchdringen. Auf ihrer Wanderung verunreinigen sie die Kulturen mit (bakteriellen) Fremdkeimen und zerstören die Pilzrasen, indem sie diese „abweiden“.

\section{Vorgehen bei Milbenbefall $\nabla$}

Milben, die sich einmal in den Pilzkolonien festgesetzt haben, sind schwer zu entfernen. Demzufolge liegt der Schwerpunkt bei prophylaktischen Maßnahmen. Die hier aufgezeigten Möglichkeiten der Prophylaxe beziehen sich ausdrücklich nur auf Pilzkulturen der Mykothek. Empfohlen wird z. B. das regelmäßige Versprühen von Insektenvertilgungsmitteln. Um ein Einwandern in die Kulturgefäße und Röhrchen zu verhindern, tränkt man die Wattestopfen mit einem Gemisch 

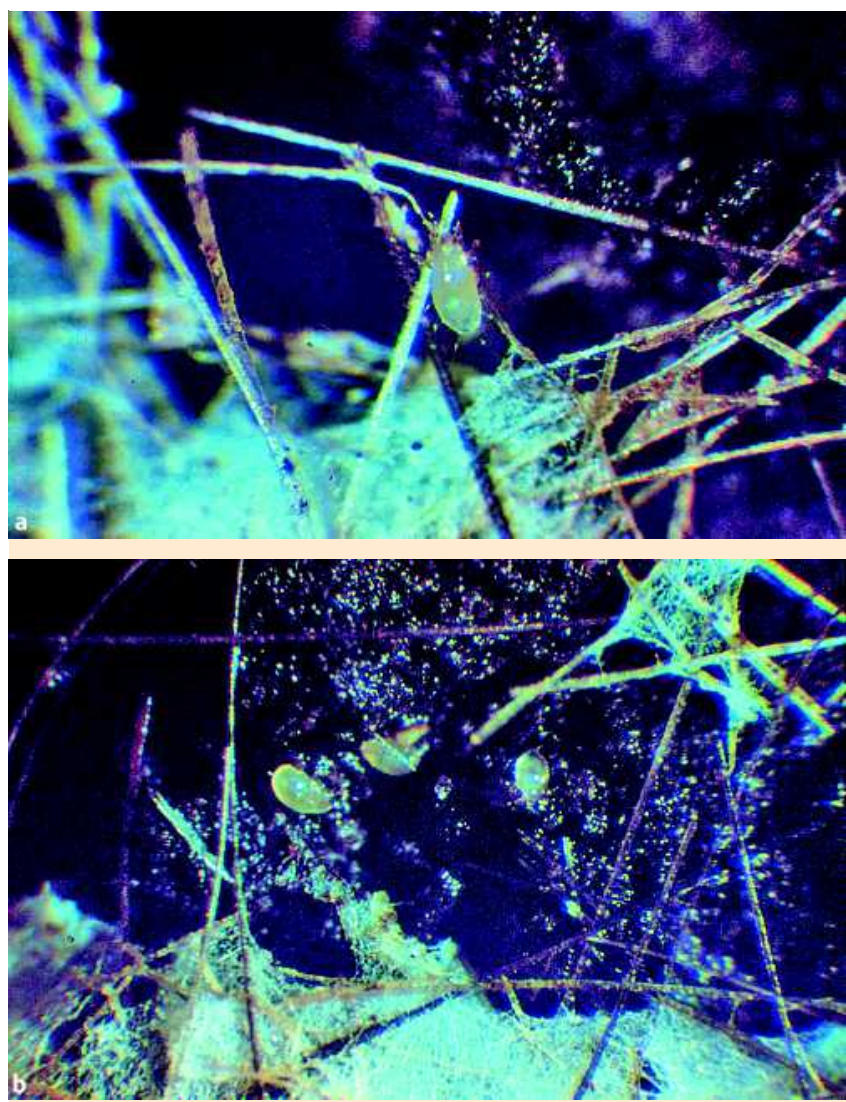

Abb. 1 a, b Pilzmilben auf Bodenschale mit Haarköder. Abbildung von Frau Dr. Christina Schönborn (1928-2001), ehemals Hautklinik der Universität Leipzig.

aus $95 \mathrm{ml}$ 95\%igem Alkohol, 0,5 $\mathrm{g} \mathrm{HgCl}_{2}$ und $5 \mathrm{ml}$ Glyzerin [6]. Nach Benedek [7] gelingt die Abtötung aller Milbenentstehungsstadien, wenn man die vermilbten Kulturen in einen verschlossenen, mit Thymolkristallen beschickten Behälter bringt. Ebenso führt ein vierzehntägiger Aufenthalt in der Tiefkühltruhe bei $-20^{\circ} \mathrm{C}$ zum Absterben der Schädlinge. Nibley and Newton [8] benutzten zur Entmilbung von Pilzkulturen Nährböden, denen vor dem Sterilisieren 0,01\% Lindan (in Pulverform) zugesetzt worden war. Die Pilze wuchsen völlig normal, während die Milben innerhalb von 3 min nach Kontakt mit dem Medium zugrunde gingen. Einen ähnlichen Effekt sollte man von Permethrin erwarten, wobei es über letztere Substanz in Hinblick auf Pilzmilben keine Erfahrung gibt.

Üblich war es lange Zeit, auch um den Milbenbefall zu vermeiden, die Pilzkulturen der Mykothek in den Schrägagarröhrchen bzw. Glaskolben mit Paraffin (Paraffinum liquidum) zu überschichten. Heute werden die zu bewahrenden Pilzstämme besser bei $-20^{\circ} \mathrm{C}$ oder $-80^{\circ} \mathrm{C}$ eingefroren. Nachteil ist, dass mitunter jedoch insbesondere Dermatophyten danach nicht wieder zu revitalisieren sind.

Eine letzte (verzweifelte) Möglichkeit ist die Vernichtung der Pilzmilben gemeinsam mit den befallenen Pilzkulturen, indem man diese bei $121^{\circ} \mathrm{C}$ autoklaviert, natürlich unter Verlust des mitunter wertvollen, lange gehegten, möglicherweise seltenen Pilzisolates!

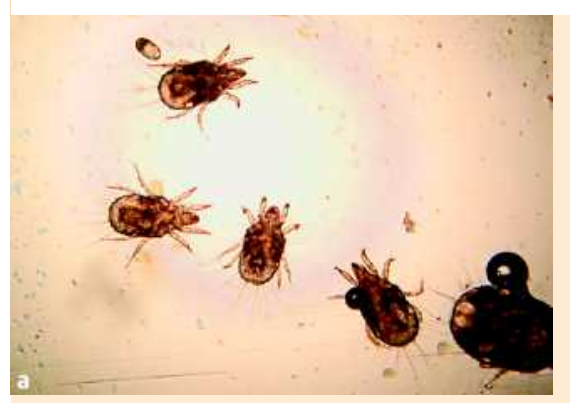

Abb. 2 a-c Pilzmilben von einer Dermatophytenkultur mit Trichophyton rubrum.
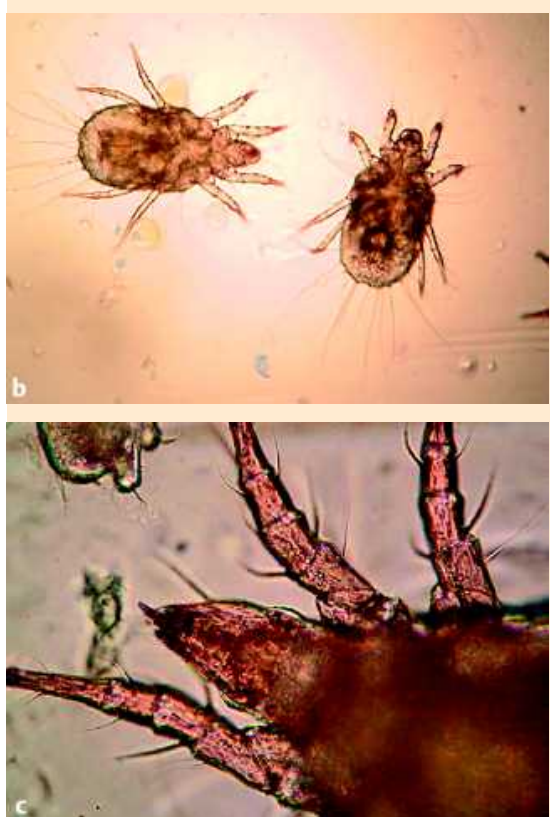

Abstract

Enemies in the Lab - Mite Muck in the Mycotheca $\nabla$

Different mites, e. g. Tarsonemus interruptus, Tarsonemus fusarii Cooreman 1941 and Tarsonemus confuses, predominantly attack and destroy - sometimes irreversibly - long time kept fungal cultures, in particular the so called mycotheca. After the mite muck is diagnosed there are few possibilities for treatment. First of all is to prevent the mite attacks by prophylactic means.

\section{Literatur}

1 Geeraerts J. Attraction of Tarsonemus fusarii Cooreman 1941 by various fungi. Mykosen 1974; 17: 27-32

2 Götz H, Reichenberger M. Tarsonemus fusarii Cooreman, a mite destroying fungus cultures. Hautarzt 1953; 4: 266-268

3 Reiss F, Caroline L. Tarsonemus confusus, contaminant of fungus cultures. AMA Arch Derm Syphilol 1953; 68: 728 - 730

4 Janke D, Lubkowitz E. Mites of the group Tarsonemus (Tarsonemus fusarii Cooreman 1941) as contaminators of fungus cultures. Klin Wochenschr 1953; 31: 289-290

5 Heidenbluth I. Milben in Dermatophytenkulturen. Dermatol W-schr 1961; 143: 244-249

6 Schönborn C. Spezielle Pilzdiagnostik. In: Wildführ G, Wildführ W (Hrsg). Medizinische Mikrobiologie, Immunologie und Epidemiologie (Band IV/2). 2. neu bearbeitete, erweiterte Auflage. Leipzig: Georg Thieme Verlag, 1982: 691 - 746

7 Benedek T. Fragmenta mycologica. IV. Use of thymol as an acaricidal agent against infestation of fungus cultures and mycotheca with acari (mites). Mycopathologia. Den Haag 1963; 19: 87

8 Nibley C Jr., Newton A. Use of lindane to control mites in fungous cultures. J Invest Derm 1957; 28: 373 - 375 